\title{
AOR
}

Selected Papers of \#AolR2020:

The $21^{\text {st }}$ Annual Conference of the

Association of Internet Researchers

Virtual Event / 27-31 October 2020

\section{EVERY CLICK YOU MAKE: ALGORITHMIC LITERACY AND THE DIGITAL LIVES OF YOUNG ADULTS}

\author{
Monica Jean Henderson \\ University of Toronto \\ Leslie Regan Shade \\ University of Toronto \\ Katie Mackinnon \\ University of Toronto
}

Critical digital literacy comprises subsets of medium- and content-related skills necessary for digital privacy and digital citizenship. Frameworks for defining and evaluating digital literacy proliferate in academia and policymaking (Eshet, 2012; Nichols \& Stornaiuolo, 2019; Pangrazio, 2016; Pangrazio \& Selwyn, 2019; Van Dijk \& Van Deursen, 2014). However, in a networked climate subsumed by dataveillance, algorithmic bias, political bots, and deep fakes (Burkell \& Gosse, 2019; Shepherd \& Henderson, 2019; West, 2019; Zuboff, 2019), these frameworks need to be updated. Algorithms may be the greatest determinant in sociopolitical online interactions and information gathering (Bucher, 2018; Noble, 2018), and without a multivalent literacy of algorithms, nuanced understandings of digital privacy and digital citizenship may be unachievable. We therefore propose 'algorithmic literacy' become an essential element for digital literacy in young adult media education.

It is a common misconception that young people aged 18-29, or 'digital natives', automatically demonstrate advanced digital skills simply because they grew up during a time of rapid digitalization. Several researchers have debunked this misconception to highlight how intersectional aspects of gender, ability, and socioeconomic status are stronger predictors of low digital literacy than age (Helsper \& Eynon, 2010; Li \& Ranieri, 2010; Livingstone \& Helsper, 2007; West, Kraut, \& Chew 2019). We agree, and argue that assumptions of digital fluency are damaging for educational programming and policy development surrounding youth digital engagement, negatively affecting the

Suggested Citation (APA): Henderson, M. J., Shade, L. R., \& Mackinnon, K. (2020, October). Every click you make: Algorithmic literacy and the digital lives of young adults. Paper presented at AolR 2020: The $21^{\text {th }}$ Annual Conference of the Association of Internet Researchers. Virtual Event: AolR. Retrieved from http://spir.aoir.org. 
digital lives of young adults. Following a tradition of participatory (rather than protectionist) research about youth privacy online (boyd, 2014; Chen, Poland, \& Skinner, 2007; Livingstone, 2008; Rodríguez \& Brown, 2009; Smith, Shade, \& Shepherd, 2017), our research foregrounds young adults' practices and perspectives on algorithmic culture in order to co-develop a framework for algorithmic literacy.

Our paper shares findings from a participatory project co-designing an algorithmic literacy toolkit with young adults as co-researchers and participants. This research was hosted by the Jackman Humanities Institute Scholars in Residence (SiR) Program at the University of Toronto, an intensive four-week residency promoting undergraduate research. Alongside our students as co-researchers, we created a curriculum focusing on reviewing the current critical scholarly literature, policy, and popular discourse on algorithms. Due to COVID-19, the program was moved to an online format where we met every morning on Zoom to discuss the readings, meet with invited speakers, and brainstorm ideas for the toolkit. After two weeks of intensive research, our student coresearchers met amongst themselves to devise a sustainable, 'living-document' type of toolkit. The process began with the development of a mission statement which centres the empowerment of social sciences and humanities students to engage in tech justice. The toolkit followed, comprising a website (thealgorithmicyou.com), an Instagram page (@thealgorithmicyou), and a Medium blog (@thealgorithmicyou). Reflected in the name, The Algorithmic You, the toolkit uses an intersectional lens to facilitate peer-oriented 'self-discovery' of how algorithmic mechanisms shape and produce interactions in the everyday lives of young adults.

This project is done in conjunction with The eQuality Project, a SSHRC Partnership that is dedicated to the creation of new knowledge about young people's use of networked spaces, with an emphasis on privacy and equality issues. The development of an algorithmic literacy toolkit interacts meaningfully with the mandate of the partnership, in its engagement with the lived experiences of young adults to co-create a toolkit that addresses the needs and concerns of their peers. This model of digital literacy development resembles projects like Project Information Literacy's "The Algorithm Study" (https://www.projectinfolit.org/algo study.html) or the UnBias project's "Fairness Toolkit" (https://unbias.wp.horizon.ac.uk/fairness-toolkit/), both of which build tools that engage university students in digital interventions.

This research makes several contributions to the scholarly field of internet research. First, it provides a participatory model for digital skills development. Second, we demonstrate how centering young adults' perspectives in the research process and in the algorithmic literacy toolkit can both a) empower youth to conduct critical investigations into today's central issues of dataveillance, internet wellbeing, and artificial intelligence/machine learning, and b) encourage them to take personal and collective ownership over their digital privacy. Reorienting algorithmic literacy within the youth perspective also helps build a foundation for healthy internet futures. Finally, our key output, the algorithmic literacy toolkit, is an easily spreadable resource for use across public education, media literacy, and internet safety, and privacy networks. We argue that centering youth in internet research has transformative potential for predisposing what our digital lives will look like in the pivotal years to come. 


\section{References}

boyd, d. (2014). It's complicated: The social lives of networked teens. New Haven, CT: Yale University Press.

Bucher, T. (2018). If...then: Algorithmic power and politics. Oxford, UK: Oxford University Press.

Burkell, J., \& Gosse, C. (2019). Nothing new here: Emphasizing the social and cultural context of deepfakes. First Monday, 24(12).

Chen, S., Poland, B., \& Skinner, H. A. (2007). Youth voices: Evaluation of participatory action research. Canadian Journal of Program Evaluation, 22(1), 125-150.

Eshet, Y. (2012). Thinking in the digital era: A revised model for digital literacy. Issues in Information Science and Information Technology, 9, 267-276.

Eubanks, V. (2012). Digital dead end: Fighting for social justice in the information age. Cambridge, MA: MIT Press.

Helsper, E. J., \& Eynon, R. (2010). Digital natives: Where is the evidence? British Educational Research Journal, 36(3), 503-520.

Li, Y., \& Ranieri, M. (2010). Are digital natives really digitally competent?-A study on Chinese teenagers. British Journal of Educational Technology, 41(6), 1029-1042.

Livingstone, S. (2008). Taking risky opportunities in youthful content creation:

Teenagers' use of social networking sites for intimacy, privacy and self-expression. New Media \& Society, 10(3), 393-411.

Livingstone, S., \& Helsper, E. (2007). Gradations in digital inclusion: Children, young people, and the digital divide. New Media \& Society, 9(4), 671-696.

Nichols, T. P., \& Stornaiuolo, A. (2019). Assembling "digital literacies": Contingent pasts, possible futures. Media and Communication, 7(2), 14-24.

Noble, S. U. (2018). Algorithms of oppression. New York, NY: New York University Press.

Pangrazio, L. (2016). Reconceptualising critical digital literacy. Discourse: Studies in the Cultural Politics of Education, 37(2), 163-174.

Pangrazio, L. \& Selwyn, N. (2018). 'Personal data literacies': A critical literacies approach to enhancing understandings of personal digital data. New Media \& Society, 1(2), 419-437. 
Rodríguez, L. F., \& Brown, T. M. (2009). From voice to agency: Guiding principles for participatory action research with youth. New Directions for Youth Development, 2009(123), 19-34.

Smith, K. L., Shade, L. R., \& Shepherd, T. (2017). Open privacy badges for digital policy literacy. International Journal of Communication, 11, 2784-2805.

Shepherd, T., \& Henderson, M. J. (2019). Digital literacy in digital policy. Canadian Journal of Communication Policy Portal, 44, 51-56.

Van Dijk, J. A. G. M., \& Van Deursen, A. J. A. M. (2014). Digital skills: Unlocking the information society. New York, NY: Palgrave Macmillan.

West, M., Kraut, R., \& Chew, H. E. (2019). I'd blush if I could: Closing gender divides in digital skills through education. EQUALS Skills Coalition. Paris, France: UNESCO.

West, S. M. (2019). Data capitalism: Redefining the logics of surveillance and privacy. Business \& Society, 58(1), 20-41.

Zuboff, S. (2019). The age of surveillance capitalism: The fight for a human future at the new frontier of power. NY: PublicAffairs Books. 